\title{
Effects of Rivastigmine and Donepezil on Brain Acetylcholine Levels in Acetylcholinesterase-Deficient Mice
}

\author{
Runa S. Naik ${ }^{a}$, Joachim Hartmann ${ }^{a}$, Cornelia Kiewert ${ }^{a}$, Ellen G. Duysen ${ }^{b}$, Oksana Lockridge $^{b}$ and \\ Jochen Klein ${ }^{\mathrm{a}, \mathrm{c}}$ \\ a Department of Pharmaceutical Sciences, School of Pharmacy, Texas Tech University Health Science Center, 1300 Coulter \\ Dr, Amarillo, TX 79106, USA. ${ }^{\mathrm{b}}$ Eppley Institute, University of Nebraska Medical Center, Omaha, Nebraska, USA ${ }^{\mathrm{c}}$ \\ Department of Pharmacology, Goethe University of Frankfurt, Max-von-Laue-Str. 9, 60438 Frankfurt, Germany.
}

Received March 3, 2009; Revised, April 1, 2009; Accepted, April 2, 2009; Published April 3, 2009

\begin{abstract}
Purpose. Alzheimer's disease is characterized by a dysfunction of central cholinergic systems and is treated by inhibitors of acetylcholinesterase (AChE). This study tests the effect of two AChE inhibitors in therapeutic use, rivastigmine and donepezil, in mice that are devoid of AChE (AChE-/- mice). Rivastigmine is an inhibitor of both AChE and butyrylcholinesterase (BChE) whereas donepezil is a selective inhibitor of AChE. Methods. We have used in vivo microdialysis to investigate the effects of the two drugs on the extracellular concentration of acetylcholine (ACh) in the hippocampus of AChE-/- mice. Results. Extracellular ACh levels in the hippocampus were 30-fold elevated in AChE-/- mice compared to wild-type (AChE $+/+$ ) animals. Infusion of rivastigmine (1 and $10 \mu \mathrm{M})$ caused a further doubling of ACh levels in AChE-/- mice within 90-120 min. In contrast, infusion of donepezil $(1 \mu \mathrm{M})$ did not affect hippocampal ACh levels in AChE-/- mice although it increased ACh levels more than twofold in wild-type mice. Conclusions. In the absence of AChE, rivastigmine enhances the levels of extracellular ACh by inhibiting BChE. This finding may be of therapeutic relevance because BChE activity is preserved, but AChE activity is strongly decreased, in late-stage Alzheimer's disease.
\end{abstract}

\section{INTRODUCTION}

Central cholinergic neurons are involved in a wide variety of brain functions, including attention, cognition, learning, memory, control of sleep and wakefulness, motor function, and many others [1]. Dysfunctions of central cholinergic systems, while involved in a variety of neuropsychiatric disorders, are particularly prominent in senile dementias such as Alzheimer's disease (AD) and dementia with Lewy bodies (DLB) [2,3]. In AD, degeneration of basal forebrain neurons reduces cholinergic tone in the cortex and hippocampus and strongly contributes to the extent of cognitive dysfunction in patients. In DLB, which involves multiple neurotransmitter systems, the cholinergic system shows the most prominent neurodegeneration, which correlates with disease severity [4].

Acetylcholine (ACh) is the only classical neurotransmitter that - after release into the synaptic cleft - is inactivated by enzymatic hydrolysis. Acetylcholinesterase (AChE, EC 3.1.1.7) was identified as the enzyme responsible for termination of cholinergic transmission by cleavage of ACh to acetate and choline; AChE is found in cholinergic synapses in the brain as well as in autonomic ganglia, the neuromuscular junction, and the target tissues of the parasympathetic system [5]. Inhibition of AChE by cholinesterase inhibitors, such as donepezil and rivastigmine, causes an increase of extracellular ACh levels in the brain of rodents [6,7]. Treatment of AD and DLB patients with cholinesterase inhibitors causes symptomatic benefit and seems to delay disease progression for 6-12 months [8,9].

Butyrylcholinesterase (BChE, EC 3.1.1.8) is an additional cholinesterase only found in mammals and birds [10].

\footnotetext{
Corresponding Author: Jochen Klein, Ph.D., Professor of Pharmacology and Clinical Pharmacy, Goethe University of Frankfurt, Biozentrum N260, Max-von-Laue-Str. 9, 60438 Frankfurt, Germany. E-mail: klein@em.uni-frankfurt.de
} 
Human BChE (accession \#P06276) shares 52\% amino acid identity with AChE (accession \#P22303) but is coded by a separate gene. It is widely distributed in the body but its function is poorly characterized; one suggested function of BChE in plasma is protection of AChE against inactivation by naturally occurring esterase inhibitors. In the brain, BChE is largely expressed by glial cells although some data support its presence in cell bodies and proximal dendrites of certain neuronal populations, e.g. in thalamus and hippocampus [11]. Recently, brain BChE has garnered much interest because of suggestions that it may contribute to ACh hydrolysis in AD $[12,13]$. BChE was shown to be functional in the brain of AChE-knockout mice [14,15]. Moreover, an increase of cortical ACh levels was observed after treatment of rats with a BChE-selective cholinesterase inhibitor [16]. Importantly, in severe $\mathrm{AD}$, AChE activity is known to decrease by as much as $85 \%$ during the course of disease while BChE activity remains unaltered or may even increase $[17,18]$. To enhance ACh levels in severe $\mathrm{AD}$, inhibitors of $\mathrm{BChE}$ have been proposed as potential therapeutic drugs [19]. This approach could now be tested experimentally because mice were created that are devoid of AChE activity [14].

AChE-/- mice are viable but show a phenotype that is consistent with peripheral cholinergic hyperactivity, including muscle weakness; because of the latter, they have to be fed a liquid diet to survive [20]. The mice exhibit persistent tremors and are seizure-prone, two characteristics that suggested cholinergic hyperactivity in the brain [14,21]. Brain morphology and central cholinergic pathways appear normal in these mice; BChE levels are unchanged $[15,21]$. We recently reported that microdialysis studies are feasible in these animals, and that brain (hippocampal) extracellular ACh levels are dramatically increased [22,23]. Furthermore, we showed that in the absence of AChE, hippocampal ACh levels are increased by bambuterol, a specific inhibitor of BChE activity [22]. This was the first unequivocal evidence for a role of brain $\mathrm{BChE}$ in mammals, namely hydrolysis of ACh when AChE activity is impeded.

In the present study, we used AChEdeficient mice and microdialysis to compare two marketed drugs, rivastigmine and donepezil, for their ability to increase ACh levels in the hippocampus of AChE-/- mice.

\section{METHODS}

\section{Animals}

AChE-/- mice in strain 129S6/SvEvTac were created and genotyped in the Lockridge lab as previously described [14]. These mice had no detectable AChE activity in any tissue. Experiments were performed in adult male and female AChE-/and $\mathrm{AChE}+/+$ mice. Mice were housed in a facility with controlled temperature and humidity and a day/night cycle of 12/12 hours. They had free access to food and water. As described [20], AChEdeficient mice were unable to chew pelleted food and were maintained on a liquid diet (Ensure ${ }^{\circledR}$ Fiber with FOS, vanilla flavor, Abbott Laboratories, Columbus, $\mathrm{OH}$ ). All procedures were in accordance with NIH guidelines and were approved by the local Institutional Animal Care und Use Committee at TTUHSC.

\section{Microdialysis experiments}

Mice were anesthetized with isoflurane (induction dose $4 \%$, maintenance dose $1-1.5 \% \mathrm{v} / \mathrm{v}$ ) in a $25 \% / 75 \%$ mixture of oxygen and nitrous oxide and placed in a stereotaxic frame. Self-made I-shaped, miniature, concentric dialysis probes with an exchange length of $1 \mathrm{~mm}$ were implanted in the right dorsal hippocampus using the following coordinates (from bregma): AP $-2.0 \mathrm{~mm}$; L -1.8 $\mathrm{mm}$; DV $-2.3 \mathrm{~mm}[22,23]$. The mice were allowed to recover over night, and experiments were carried out on two consecutive days after probe implantation in freely moving animals.

On the experimental days, the microdialysis probes were perfused with artificial cerebrospinal fluid (aCSF; $147 \mathrm{mM} \mathrm{NaCl}, 4 \mathrm{mM} \mathrm{KCl}, 1.2 \mathrm{mM}$ $\mathrm{CaCl}_{2}$ and $1.2 \mathrm{mM} \mathrm{MgCl}_{2}$ ) without cholinesterase inhibitor. The perfusion rate was $1 \mu \mathrm{l} / \mathrm{min}$, and efflux from the microdialysis probe was collected in intervals of $15 \mathrm{~min}$. After equilibration, samples were collected for $60 \mathrm{~min}$ to establish baseline values of ACh. Subsequently, the perfusion fluid was switched to aCSF containing rivastigmine or donepezil (both drugs were obtained in $>99 \%$ purity from Novartis Co., East Hanover, NJ). After 90 min, perfusion fluid was switched back to drug-free 
aCSF and mice were further monitored for a period of at least 2 hours.

On day 3 after probe implantation, the mice were sacrificed. Brains were taken out and the right hemispheres, where the microdialysis probe was located, were fixed by immersion in buffered formaldehyde solution. After fixation, coronal sections were made manually with a razor blade and visually inspected to confirm the probe location in the hippocampus. All probes were observed to be located within the hippocampus.

\section{HPLC analysis of acetylcholine}

ACh in dialysates was determined by microbore HPLC-ECD using a metal-free system from Bioanalytical Systems (West Lafayette, IN) which consisted of a low-speed pump (BAS PM-80), separation column (SepStik, $530 \times 1 \mathrm{~mm}$ ), enzyme reactor $(50 \times 1 \mathrm{~mm})$ carrying immobilized AChE and choline oxidase, and electrochemical detector (BAS LC-4C) with a platinum electrode operating at $+0.5 \mathrm{~V}$ relative to the $\mathrm{Ag} / \mathrm{AgCl}$ reference electrode. ACh was retained on the separation column, cleaved to choline and acetate by AChE, and choline was oxidized to $\mathrm{H}_{2} \mathrm{O}_{2}$ by choline oxidase which was subsequently detected electrochemically. The mobile phase consisted of $29 \mathrm{mM}$ monobasic sodium phosphate, $22 \mathrm{mM}$ sodium acetate (both HPLC-grade, EM Science, Gibbstown, NJ) and $0.32 \mathrm{mM}$ disodium-EDTA (Fisher Scientific, Pittsburgh, PA), adjusted to $\mathrm{pH}$ 8.4 and preserved with Kathon CG (Rohm and Haas, Croydon, UK). The flow rate was $120 \mu \mathrm{l} / \mathrm{min}$. At an injection volume of $5 \mu \mathrm{l}$, the detection limit of this system was 5-10 fmol/injection (coefficient of variance at $10 \mathrm{fmol}: 19 \%)$.

\section{STATISTICS}

Time courses of acetylcholine release (Figs. 1 and 2) were compared using two-way analysis of variance for repeated measurements (software: GraphPad Prism $\left.{ }^{\circledR}\right)$. This is the appropriate statistical procedure to compare two time courses with respect to interaction, column factor and row factor. $\mathrm{P}$ values given in the figure legends refer to the column factor which gives the probability that the curves are different from each other, taking time courses into account.

\section{RESULTS}

\section{Extracellular levels of acetylcholine in untreated mice}

In AChE-/- mice, average levels of ACh in the microdialysates were $775 \pm 275 \mathrm{fmol} / 5 \mathrm{~min}$ in mice that were later treated with rivastigmine (mean \pm S.D., N=12, Fig. 1) and $793 \pm 264 \mathrm{fmol} / 5 \mathrm{~min}$ in the mice that were later treated with donepezil ( $\mathrm{N}=6$, Fig. 2). These values were about 30 -fold higher $(\mathrm{p}<0.001)$ than those measured in wild-type $\mathrm{AChE}+/+$ mice which were $26.7 \pm 7.9 \mathrm{fmol} / 5 \mathrm{~min}$ (N=6, Fig. 3).

\section{Effects of rivastigmine in AChE-/- mice}

When administered through the microdialysis probe to AChE-/- mice, rivastigmine $(1 \mu \mathrm{M})$ caused an immediate increase of hippocampal ACh levels by $30-50 \%$. ACh levels continued to rise during the 60 min infusion and even after the infusion fluid had been switched back to aCSF (Fig. 1). Maximum elevations of ACh (180-200\% of baseline values) were observed two to three hours after the start of the infusion.

Rivastigmine at a higher concentration (10 $\mu \mathrm{M})$ did not further increase ACh levels. Infusion of saline was without effect (Fig. 1).

\section{Effects of donepezil in AChE-/- mice}

When infused into the hippocampus of AChE-/mice, donepezil $(1 \mu \mathrm{M})$ did not cause a significant change in the extracellular ACh level (Fig. 2). DMSO (0.5\%) in which donepezil had to be dissolved also did not affect hippocampal ACh levels (Fig. 2).

\section{Effects of donepezil in $\mathrm{AChE}+/+$ mice}

As donepezil was inactive in AChE-/- mice, we also tested the drug in the same concentration in wildtype mice. Infusion of donepezil $(1 \mu \mathrm{M})$ in AChE+/+ mice rapidly increased hippocampal ACh levels by $150 \%$ within 45 minutes (Fig. 3). 


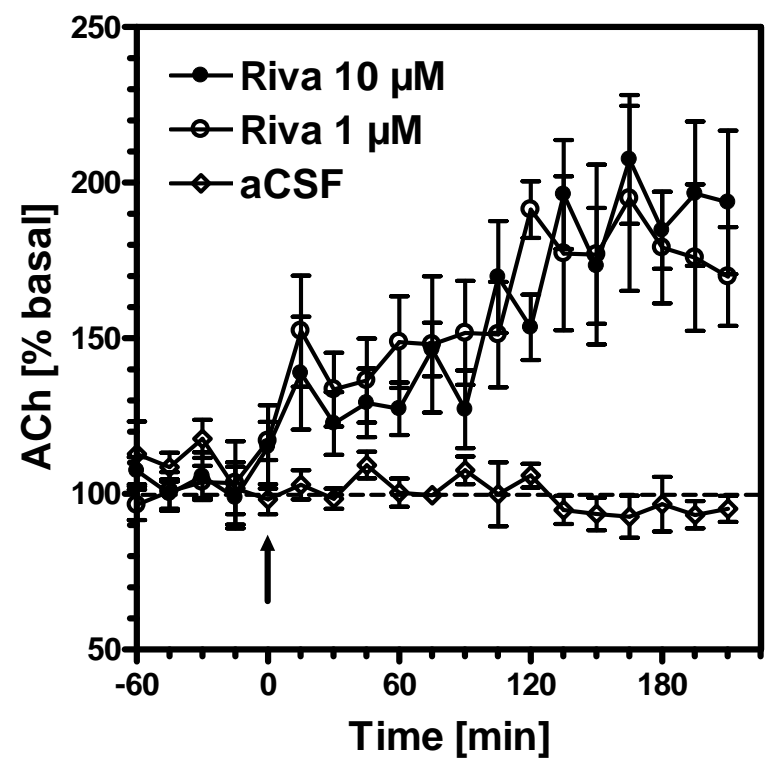

Figure 1. Efflux of acetylcholine (ACh) from mouse hippocampus during infusion of rivastigmine (Riva) to AChE-deficient mice. Rivastigmine was infused for 60 min starting at time zero (see arrow), at 1 or $10 \mu \mathrm{M}$. Artificial CSF (aCSF, see Methods) was infused as a control ( $\mathrm{N}=6$ each). Data are means \pm S.E.M. and are given as percentages of basal ACh efflux observed before the start of rivastigmine infusions. Statistical analysis (two-way ANOVA for repeated measurements, GraphPad Prism ${ }^{\circledR}$ ): $\quad$ Rivastigmine $1 \mu \mathrm{M}$ vs. $\mathrm{NaCl}$ : $\mathrm{F}_{1,180}=33.43, \mathrm{p}=0.0002$. Rivastigmine $10 \mu \mathrm{M}$ vs. $\mathrm{NaCl}: \mathrm{F}_{1,180}=69.67, \mathrm{p}<0.0001$. Rivastigmine $1 \mu \mathrm{M}$ vs. rivastigmine $10 \mu \mathrm{M}: \mathrm{F}_{1,180}=0.01, \mathrm{p}=0.93$.

\section{DISCUSSION}

Butyrylcholinesterase is an enzyme of unknown physiologic function in mammals. It was suggested, however, that it may protect AChE from inactivation by scavenging potentially toxic AChE inhibitors [5,10]. The AChE-deficient mouse is a valuable model to study the significance of BChE expression in the brain in the absence of AChE activity. While systemic inhibition of BChE proved to be toxic in these mice $[14,20]$, we used the microdialysis technique which allows local infusion of drugs and determination of extracellular ACh in defined regions of the brain thus avoiding systemic toxicity. We chose to measure ACh levels in the hippocampus, a brain region that is important for learning and memory formation and in which cholinergic nerve endings typically deteriorate in neurodegenerative disease [24].

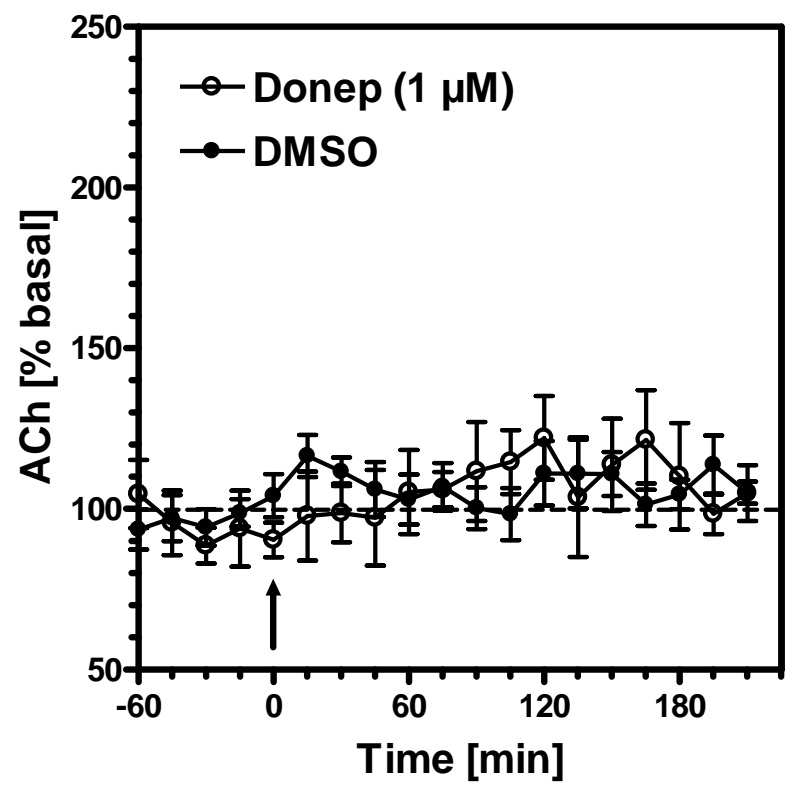

Figure 2. Efflux of acetylcholine (ACh) from mouse hippocampus during infusion of donepezil in AChE-/- mice ( $\mathrm{N}=6)$. Donepezil (Donep, $1 \mu \mathrm{M})$ was infused for $60 \mathrm{~min}$ starting at time zero (see arrow). As a control, mice received aCSF containing 0.5\% DMSO which was the amount of DMSO that was also used to dissolve donepezil in aCSF. Data are means \pm S.E.M. and are given as percentages of basal ACh efflux observed before the start of donepezil infusions. Statistical analysis (two-way ANOVA for repeated measures, GraphPad Prism $\left.{ }^{\circledR}\right)$ : DMSO vs. donepezil, $\mathrm{F}_{1,144}=0.01 ; \mathrm{p}=0.94$.

In agreement with our earlier study [22], extracellular levels of ACh in the hippocampus of AChE-/- mice were dramatically increased (30-fold in this study). In the present study, we infused two therapeutically used AChE inhibitors to investigate the role of cholinesterase for ACh hydrolysis. We first tested rivastigmine which is a dual inhibitor of $\mathrm{AChE}$ and BChE [19]. Literature reports indicate increases of brain ACh, measured by microdialysis, when rivastigmine was given orally to rats $[7,25,26]$. 


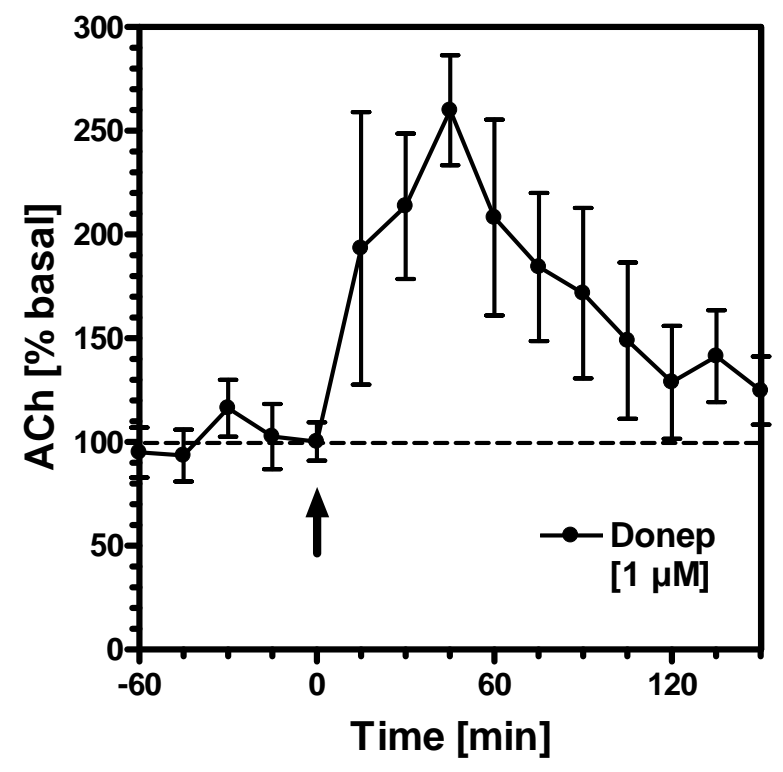

Figure 3. Efflux of acetylcholine (ACh) from mouse hippocampus during infusion of donepezil in wild-type AChE+/+ mice (strain 129Sv; N=6). Donepezil (Donep, $1 \mu \mathrm{M}$ ) was infused for $60 \mathrm{~min}$ starting at time zero (see arrow). Data are means \pm S.E.M. and are given as percentages of basal ACh efflux observed before the start of donepezil infusions.

In our hands, rivastigmine caused an increase of hippocampal ACh levels when infused at 1-10 $\mu \mathrm{M}$ in AChE-/- mice. In the absence of AChE, this increase of ACh must be due to inhibition of $\mathrm{BChE}$, a conclusion that is in agreement with our previous findings [22]. As a carbamate, rivastigmine has a pseudo-irreversible mechanism of action; it binds and inactivates cholinesterases for several hours $[27,28]$. The slow onset of action as well as the prolonged activity of rivastigmine even after infusion was stopped support the idea that rivastigmine causes a slow-onset, pseudoirreversible inactivation of $\mathrm{BChE}$ in the brain of AChE-/- mice.

Donepezil is an allosteric, reversible inhibitor of AChE which is largely inactive as a BChE inhibitor ( $\mathrm{IC}_{50}$ for human AChE: $22 \mathrm{nM}$; $\mathrm{IC}_{50}$ for human BChE: 4.1 $\mu \mathrm{M}) \quad[12,19]$. The concentration of donepezil used for infusion $(1 \mu \mathrm{M})$ was much higher than its $\mathrm{IC}_{50}$ value for AChE (22 $\mathrm{nM})$. With this concentration, donepezil did not affect ACh levels in AChE-deficient mice. This finding supports the selective action of donepezil on AChE and demonstrates a lack of inhibition of BChE by donepezil in vivo.

To document that donepezil at $1 \mu \mathrm{M}$ is capable of inhibiting AChE in vivo, we repeated the experiments with donepezil in wild-type mice. At 1 $\mu \mathrm{M}$, donepezil significantly increased ACh levels in those mice to $250 \%$ of basal values. As expected, the donepezil effect disappeared when infusion was discontinued because donepezil is a reversible inhibitor of AChE. These data demonstrate that donepezil was present locally in sufficient quantities to inhibit murine AChE in vivo. In earlier reports in which donepezil was given systemically, it was also found to increase extracellular ACh levels in the brain of rats $[6,25,29]$.

The present results impact on the therapeutic use of cholinesterase inhibitors for the treatment of neurodegenerative diseases with cholinergic hypofunction, such as AD and DLB. It has been argued that it may be advantageous to use selective inhibitors of AChE for treatment because they offer a lower risk of peripheral side effects [30]. On the other hand, it has been pointed out that the activity of AChE is progressively reduced in central cholinergic dysfunction; in $\mathrm{AD}$, for instance, values as low as $15 \%$ of controls have been reported in advanced disease $[17,18]$. Accordingly, some authors believe that inhibition of BChE which is preserved in $\mathrm{AD}$ - may offer advantages in advanced disease [13]. It has been estimated that in late $\mathrm{AD}$, the relative activity of $\mathrm{BChE}$ may be 11fold higher than that of AChE $[12,19]$. It seems likely, therefore, that the contribution of BChE to ACh hydrolysis in the brain increases in AD when the disease progresses. In this situation, drugs inhibiting BChE, or both AChE and BChE, may be more effective than specific AChE inhibitors.

There is some published evidence that inhibition of BChE activity may be of therapeutic relevance in dementia. BChE activity has been reported to be negatively correlated with $\mathrm{AD}$ disease severity, i.e. low BChE activity reduces disease progression (reviewed in [31]). Recent clinical trials indicated that inhibitors such as rivastigmine (which co-inhibits AChE and BChE) were effective in patients that no longer responded to AChE-selective inhibitors such as donepezil (reviewed in [32,33]). While our data give evidence that rivastigmine, but not donepezil, inhibits $\mathrm{BChE}$ activity in the brain, more clinical work is required 
to support the concept of BChE inhibition in latestage dementia.

\section{ACKNOWLEDGEMENT}

This study was supported by an unconditional grant from Novartis Co. (East Hanover, NJ). We thank Dr. S. Brannan and J. Steadman at Novartis Co. for their support.

\section{REFERENCES}

[1]. Gold PE. Acetylcholine: cognitive and brain functions. Neurobiol Learn Mem 2003; 80: 194210.

[2]. Francis PT, Palmer AM, Snape M, Wilcock GK. The cholinergic hypothesis of Alzheimer's disease: a review of progress. J Neurol Neurosurg Psychiatry 1999; 66: 137-147.

[3]. McKeith IG, Mintzer J, Aarsland A, The International Psychogeriatric Association Expert Meeting on DLB. Dementia with Lewy bodies. Lancet Neurol 2004; 3: 19-28.

[4]. Tiraboschi P, Hansen L, Alford M, Merdes A, Masliah E, Thal LJ, Corey-Bloom J. Early and widespread cholinergic losses differentiate dementia with Lewy bodies from Alzheimer disease. Arch Gen Psychiatry 2002; 59: 946951.

[5]. Soreq H, Seidman S. Acetylcholinesterase new roles for an old actor. Nature Rev Neurosci 2001; 2: 294-302.

[6]. Giacobini E, Zhu XD, Williams E, Sherman KA. The effect of the selective reversible acetylcholinesterase inhibitor E2020 on extracellular acetylcholine and biogenic amine levels in rat cortex. Neuropharmacology 1996; 35: 205-211.

[7]. Ohara T, Tanaka K, Fukaya H, Demura N, Iimura A, Seno N. SDZ ENA 713 facilitates central cholinergic function and ameliorates spatial memory impairment in rats. Behav Brain Res 1997; 83: 229-233.

[8]. Gauthier S. Advances in the pharmacotherapy of Alzheimer's disease. CMAJ 2002; 166: 616623.

[9]. Aarsland D, Mosimann UP, McKeith IG. Role of cholinesterase inhibitors in Parkinson's disease and dementia with Lewy bodies. J Geriatr Psychiatry Neurol 2004; 17: 164-171.

[10]. Darvesh S, Hopkins DA, Geula C. Neurobiology of butyrylcholinesterase. Nature Rev Neurosci 2003; 4: 131-138.

[11]. Darvesh S, Hopkins DA. Differential distribution of butyrylcholinesterase and acetylcholinesterase in the human thalamus. $\mathrm{J}$ Comp Neurol 2003; 463: 25-43.

[12]. Giacobini E. Cholinesterases: new roles in brain function and in Alzheimer's disease. Neurochem Res 2003; 28: 515-522.

[13]. Ballard CG, Greig NH, Guillozet-Bongaarts AL, Enz A, Darvesh S. Cholinesterases: roles in the brain during health and disease. Curr Alzheimer Res 2005; 2: 307-318.

[14]. Xie W, Stribley JA, Chatonnet A, Wilder PJ, Rizzino A, McComb RD, Taylor P, Hinrichs $\mathrm{SH}$, Lockridge O. Postnatal developmental delay and supersensitivity to organophosphate in gene-targeted mice lacking acetylcholinesterase. J Pharmacol Exp Ther 2000; 293: 896-902.

[15]. Mesulam MM, Guillozet A, Shaw P, Levey A, Duysen EG, Lockridge O. Acetylcholinesterase knockouts establish central cholinergic pathways and can use butyrylcholinesterase to hydrolyze acetylcholine. Neuroscience 2002; 110: 627-639.

[16]. Greig NH, Utsuki T, Ingram DK, Wang Y, Pepeu G, Scali C, Yu Q-S, Mamczarz J, Holloway HW, Giordano T, Chen D, Furukawa K, Sambamuri K, Brossi A, Lahiri DK. Selective butyrylcholinesterase inhibition elevates brain acetylcholine, augments learning and lowers Alzheimer beta-amyloid peptide in rodent. Proc Natl Acad Sci USA 2005; 102: 17213-17218.

[17]. Perry EK, Perry RH, Blessed G, Tomlinson BE. Changes in brain cholinesterases in senile dementia of Alzheimer type. Neuropathol Appl Neurobiol 1978; 4: 273-277.

[18]. Arendt T, Bruckner MK, Lange M, Bigl V. Changes in acetylcholinesterase and butyrylcholinesterase in Alzheimer's disease resemble embryonic development--a study of molecular forms. Neurochem Int 1992; 21: 381396.

[19]. Giacobini E. Cholinesterase inhibitors: new roles and therapeutic alternatives. Pharmacol Res 2004; 50: 433-440.

[20]. Duysen EG, Stribley JA, Fry DL, Hinrichs SH, Lockridge O. Rescue of the acetylcholinesterase knockout mouse by feeding a liquid diet; phenotype of the adult acetylcholinesterase deficient mouse. Brain Res Dev Brain Res 2002; 137: 43-54.

[21]. Li B, Stribley JA, Ticu A, Xie W, Schopfer LM, Hammond P, Brimijoin S, Hinrichs SH, Lockridge $\mathrm{O}$ Abundant tissue butyrylcholinesterase and its possible function in the acetylcholinesterase knockout mouse. J Neurochem 2000; 75: 1320-1331. 
[22]. Hartmann J, Kiewert C, Duysen EG, Lockridge O, Greig NH, Klein J. Excessive hippocampal acetylcholine levels in acetylcholinesterasedeficient mice are moderated by butyrylcholinesterase activity. J Neurochem 2007; 100: 1421-1429.

[23]. Hartmann J, Kiewert C, Duysen EG, Lockridge $\mathrm{O}$, Klein J. Choline availability and acetylcholine synthesis in the hippocampus of acetylcholinesterase-deficient mice. Neurochem Int 2008; 52: 972-978.

[24]. Dutar P, Bassant M-H, Senut M-C, Lamour Y. The septohippocampal pathway: structure and function of a central cholinergic system. Physiol Rev 1995; 75: 393-427.

[25]. Kosasa T, Kuriya Y, Matsue K, Yamanishi Y. Effect of donepezil hydrochloride (E2020) on basal concentration of extracellular acetylcholine in the hippocampus of rats. Eur $\mathrm{J}$ Pharmacol 1999; 380: 101-107.

[26]. Scali C, Casamenti F, Bellucci A, Costagli C, Schmidt B, Pepeu G. Effect of subchronic administration of metrifonate, rivastigmine and donepezil on brain acetylcholine in aged F344 rats. J Neural Transm 2002; 109, 1067-1080.

[27]. Bar-on P, Millard CB, Harel M, Dvir H, Enz A, Sussman JL, Silman I. Kinetics and structural studies on the interaction of cholinesterases with the anti-Alzheimer drug rivastigmine. Biochemistry 2002; 41: 3555-3564.

[28]. Groner E, Ashani Y, Schorer-Apelbaum D, Sterling J, Herzig Y, Weinstock M. The kinetics of inhibition of human acetylcholinesterase and butyrylcholinesterase by two series of novel carbamates. Mol Pharmacol 2007; 71: 1610-1617.

[29]. Kawashima K, Sato A, Yoshizawa M, Fujii T, Fujimoto K, Suzuki T. Effects of the centrally acting cholinesterase inhibitors tetrahydroaminoacridine and E2020 on the basal concentration of extracellular acetylcholine in the hippocampus of freely moving rats. Naunyn-Schmiedeberg's Arch Pharmacol 1994; 350: 523-528.

[30]. Liston DR, Nielsen JA, Villalobos A, Chapin D, Jones SB, Hubbard ST, Shalaby IA, Ramirez A, Nason D, White WF. Pharmacology of selective acetylcholinesterase inhibitors: implications for use in Alzheimer's disease. Eur J Pharmacol 2004; 486: 9-17.

[31]. Tasker A, Perry EK, Ballard CG. Butyrylcholinesterase: impact on symptoms and progression of cognitive impairment. Expert Rev Neurother 2005; 5: 101-106.

[32]. Gauthier S, Emre M, Farlow MR, Bullock R, Grossberg GT, Potkin SG. Strategies for continued successful treatment of Alzheimer's disease: switching cholinesterase inhibitors. Curr Med Res Opin 2003; 19: 707-714.

[33]. Figiel GS, Sadowsky CH, Strigas J, Koumaras B, Meng X, Gunay I. Safety and efficacy of rivastigmine in patients with Alzheimer's disease not responding adequately to donepezil: an open-label study. Primary Care Companion J Clin Psychiatry 2008; 10: 291-298. 